\title{
Implementasi Monitoring Suhu dan Kelembaban pada Budidaya Jamur Tiram dengan IOT
}

\author{
Implementation of Temperature and Humidity Monitoring \\ at Oyster Mushroom Cultivation with IOT
}

\author{
Yuli Wibowo $^{1 \bowtie}$, Febriansah Eka Prasetyadana ${ }^{1}$, Bertung Suryadharma ${ }^{1}$ \\ ${ }^{1}$ Program Studi Teknologi Industri Pertanian, Fakultas Teknologi Pertanian, Universitas Jember

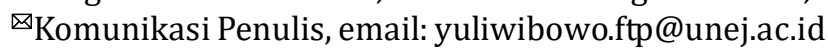 \\ DOI:http://dx.doi.org/10.23960/jtep-l.v10i3.380-391
}

Naskah ini diterima pada 2 Juli 2021; revisi pada 6 September 2021; disetujui untuk dipublikasikan pada 23 September 2021

\begin{abstract}
Oyster mushroom commodity has been widely used as raw material for processed food products, monitoring of temperature and humidity intensively, the quality will be well maintained. Monitoring at Rumah Jamur Barokah full 24 hours, so it will be difficult if done manually. This is the reason why it is necessary to design monitoring tools in maintaining the ideal temperature and humidity with the concept of the Internet of Things. This research aims to design temperature and humidity monitoring tools (IoT), and how much the increase value of time efficiency and effectiveness after the tool is implemented. The blackbox testing method is performed for performance feasibility testing, by comparing thermo-hygrometers and sensors. The result of the tool performance test at the temperature parameter obtained an error value $0.33^{\circ} \mathrm{C}$ and the DHT22 tolerance limit $\pm 0.5^{\circ} \mathrm{C}$. In the humidity parameter obtained an error of $1.8 \%$ RH and the DHT22 tolerance limit $\pm 2 \% R H$, so the DHT22 sensor feasible to use. In the analysis of efficiency calculation obtained a result of $77.95 \%$ for improved time efficiency. In the analysis of the quality effectiveness value of oyster mushrooms is less than ideal, getting an increase in value by $143 \%$ to $163 \%$.
\end{abstract}

Keywords: blackbox testing, cultivation, internet of things (IOT), monitoring, oyster mushroom

\begin{abstract}
ABSTRAK
Komoditas jamur tiram telah banyak dimanfaatkan sebagai bahan baku produk olahan makanan, dengan monitoring kondisi suhu dan kelembaban pada proses perawatan yang intensif, kualitasnya akan dapat terjaga dengan baik. Monitoring pada Rumah Jamur Barokah dilakukan selama 24 jam penuh, sehingga akan terlalu sulit apabila dilakukan secara manual. Hal ini yang menjadi alasan mengapa perlu dilakukan perancangan alat monitoring dalam menjaga suhu dan kelembaban yang ideal dengan konsep Internet of Things. Penelitian ini bertujuan untuk melakukan perancangan alat monitoring suhu dan kelembaban melalui jaringan internet (IoT), agar diketahui berapa besar peningkatan nilai efisiensi waktu dan efektivitas setelah alat di implementasikan. Metode blackbox testing dilakukan untuk uji kelayakan kinerja, dengan membandingkan thermo-hygrometer dan sensor dari alat yang dirancang. Hasil dari pengujian kinerja alat pada parameter suhu memperoleh nilai error sebesar $0,33^{\circ} \mathrm{C}$ dan batas toleransi DHT22 sebesar $\pm 0,5^{\circ} \mathrm{C}$. Pada parameter kelembaban diperoleh error sebesar 1,8\% RH dan batas toleransi DHT22 sebesar $\pm 2 \%$ RH, sehingga sensor DHT22 dapat dikatakan layak untuk digunakan. Dalam analisis perhitungan efisiensi diperoleh hasil sebesar 77,95\% untuk peningkatan efisiensi waktu. Pada analisis nilai efektivitas mutu jamur tiram kurang ideal, mendapatkan peningkatan nilai sebesar $143 \%$ menjadi $163 \%$.
\end{abstract}

Kata Kunci: blackbox testing, budidaya, internet of things (iot), jamur tiram, pengawasan

\section{PENDAHULUAN}

Urban Farming atau berkebun di tengah daerah perkotaan merupakan suatu aktivitas yang mulai diminati oleh masyarakat modern. Contoh komoditas pertanian yang dapat dibudidayakan yaitu jamur tiram. Perkembangan budidaya jamur tiram mengalami kenaikan permintaan 
dalam negeri yang meningkat setiap tahun sekitar $20 \%$ - 25\% (Nurhakim, 2018). Pada umumnya suhu yang optimum dalam budidaya jamur tiram pada fase pembentukan kumpulan benangbenang hifa / miselium berkisar antara $28{ }^{\circ} \mathrm{C}$ $30{ }^{\circ} \mathrm{C}$ dengan kelembaban 50\% - 60\%. Namun, pada tahap pembentukan tubuh buah diperlukan suhu udara antara $25{ }^{\circ} \mathrm{C}-30{ }^{\circ} \mathrm{C}$ dengan kelembaban 70\% - 95\% (Devi et al., 2018).

Rumah Jamur Barokah Jember merupakan suatu usaha mikro yang melakukan urban farming dengan komoditas budidaya jamur tiram. Sistem smart urban farming hanya membutuhkan lebih sedikit perawatan, lebih sedikit tenaga kerja dan menghemat banyak ruang (Mohammed et al., 2019). Dalam budidaya jamur tiram, usaha mikro ini sering terkendala dalam melakukan monitoring suhu dan kelembaban pada kumbung, karena nilainya yang selalu berubah sehingga perlu berkali-kali memastikan menggunakan thermo-hygrometer digital. Pada Usaha mikro Rumah Jamur Barokah belum terdapat sistem kendali yang mampu memenuhi kebutuhan pelaku usaha untuk monitoring melalui jaringan internet dan tentunya dengan harga yang terjangkau, sehingga petani dapat memeriksa suhu dan kelembaban melalui smartphone setiap saat (Bunluewong, 2021).

Konsep Internet of Things (IoT) merupakan alternatif yang dapat diterapkan dalam merancang suatu alat monitoring suhu dan kelembaban untuk pembudidayaan jamur tiram dengan cepat, mudah serta real time, sehingga mempermudah pengawasan pemilik usaha pada ruang budidaya jamur tiram. IoT telah membawa perubahan revolusioner dalam monitoring, manajemen, dan sektor analisis data (Subedi et al., 2019). Oleh sebab itu, penerapan alat ini diharapkan agar hasil budidaya jamur tiram dapat berjalan optimum.

\section{BAHAN DAN METODE}

Penelitian dilakukan di Rumah Jamur Barokah Jember. Bahan yang digunakan pada penelitian ini terdiri dari: NodeMCU ESP8266; Sensor DHT22; Kabel Jumper $10 \mathrm{~cm}$ - $20 \mathrm{~cm}$; Mini Breadboard (400 hole); Modul Breadboard Power Supply MB102; Wadah peyimpanan alat;
Adaptor DC 9V; Relay 2 Channel; Lampu LED oren dan hijau; Stop kontak; Steker; Fitting lampu; Wadah kayu lampu peringatan. Alat-alat yang digunakan adalah Laptop (Operating System Windows 10 Home 64-bit); Arduino IDE (Integrated Development Environment); Microsoft Office 2019; Software Fritzing; Atom + plugin remote-FTP; Smartphone OS Android; Hosting + Domain (my.id); Aplikasi Blynk; MySQL (Server Database); Mifi; ThermoHygrometer digital; Alat Tulis; dan Stopwatch.

Metode yang digunakan dalam penelitian ini adalah blackbox testing atau behavioral testing yang merupakan pengujian dengan memiliki fokus pada kebutuhan fungsional dari suatu perangkat sistem, pengujiannya dilakukan dengan menghitung jumlah fitur fungsional yang berjalan dengan baik kemudian dibandingkan dengan seluruh fitur fungsionalitas yang ada, sehingga pengujian ini memeriksa perangkat lunak, perangkat keras serta aplikasi secara sekaligus (Agustianto et al., 2021).

Skala Guttman menggunakan analisis deskriptif dengan jawaban tegas "Ya" atau "Tidak", sehingga diharapkan dapat memberikan informasi dalam metode blackbox testing. Tahapan penelitian dapat dilihat pada diagram alir berikut ini (Gambar 1) dan untuk skema pembuatan rangkaian keseluruhan dapat dilihat pada (Gambar 2).

Dalam perancangan alat monitoring suhu dan kelembaban ini terdapat beberapa tahapan penting yang harus dilakukan agar dapat di implementasikan pada budidaya jamur tiram. Tahapan tersebut terbagi menjadi beberapa yaitu:

1. Tahap Pemrograman Mikrokontroler merupakan kegiatan yang terbagi menjadi 3 bagian yang memiliki peran yang berbeda, akan tetapi tetap berkesinambungan yaitu pemrograman mikrokontroler, pemrograman Blynk, dan pemrograman Web.

2. Tahap Pengujian Sistem, disini rancangan alat akan di uji untuk implementasi pada kumbung jamur tiram sebelum digunakan untuk monitoring pada waktu yang sebenarnya. Uji yang digunakan sebagai berikut: Uji Kinerja (Perbandingan dilakukan dengan nilai pembacaan data sebanyak 30 kali) Interval 


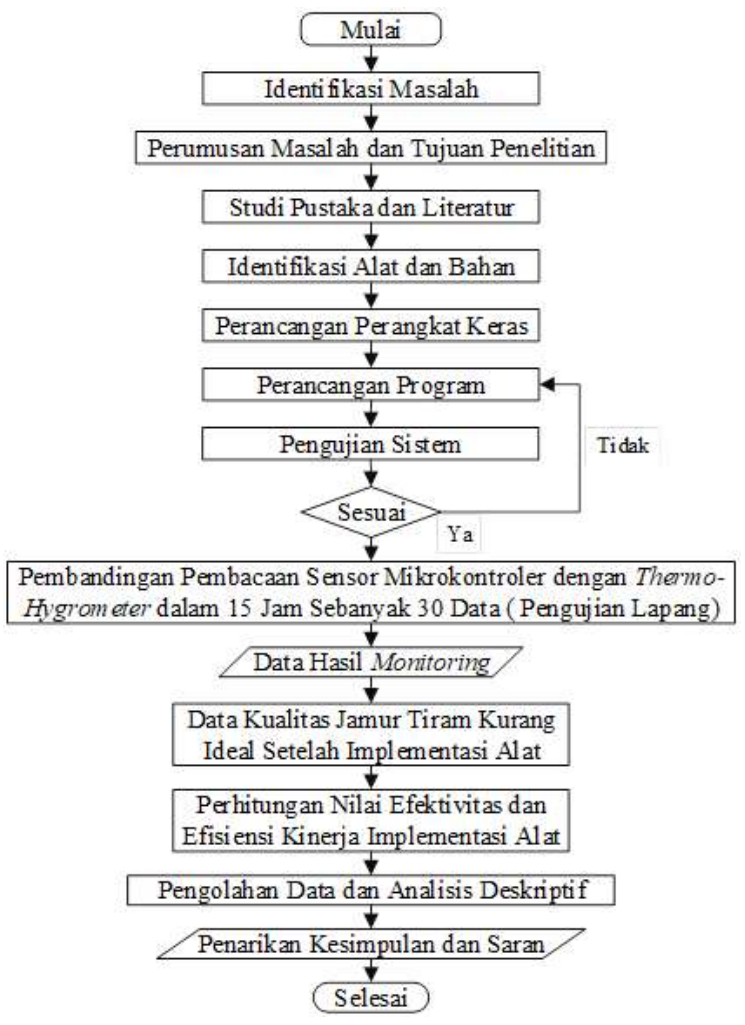

Gambar 1. Diagram Alir Penelitian

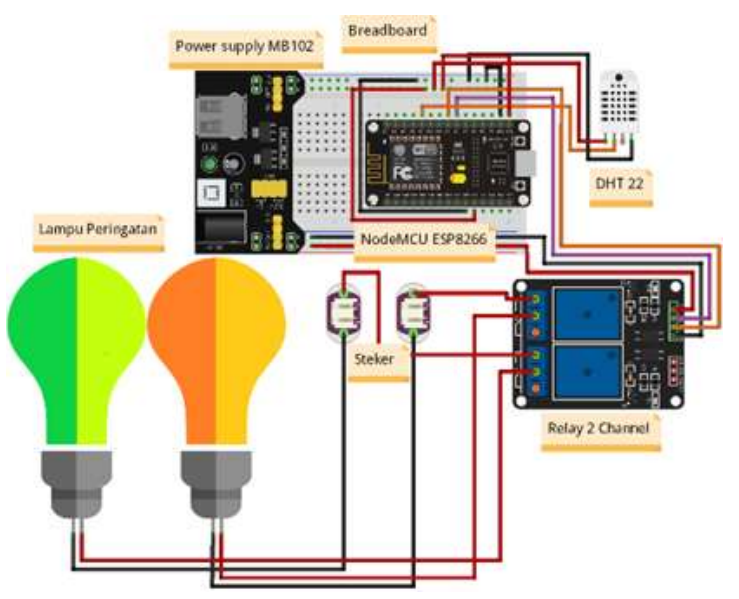

Gambar 2. Skema Pembuatan Rangkaian Keseluruhan

waktu jeda 30 menit selama 15 jam (Hamdi dan Baharuddin, 2014). Banyaknya sampel minimal yang digunakan dalam pengujian perbandingan adalah 30 data; pengujian Lapang; dan Uji Efisiensi dan Efektivitas Kinerja

3. Tahap Hasil dan Analisis pada tahap ini didapatkan hasil yang nantinya akan di analisis output rancangan alat apakah berfungsi baik. Beberapa analisis yang digunakan yaitu: a. Analisis data uji kinerja menggunakan skala Guttman dan perhitungan untuk aspek functionality menggunakan standar perhitungan dari ISO/IEC 9126 (2001) dengan persamaan:

$$
\mathrm{X}=1-\frac{\mathrm{A}}{\mathrm{B}}
$$

Pada analisis ini, variabel A merupakan jumlah butir instrumen yang diberi jawaban "Tidak" atau bernilai 0 . Sedangkan variabel B merupakan jumlah 
butir instrumen yang diberi jawaban "Ya" atau bernilai 1. Interpretasi pengukuran dari ISO/IEC 9126 yaitu $0<=\mathrm{X}<=1$. Sebuah perangkat lunak dikatakan baik dalam aspek functionality jika $\mathrm{X}$ mendekati 1.

b. Analisis data implementasi alat monitoring pada proses budidaya jamur tiram yang menunjukkan kesesuaian alat dengan kondisi nyata

c. Analisis Efisiensi dan Efektivitas Kinerja

4. Tingkat efisiensi waktu dapat ditentukan menggunakan Persamaan 2. Pengukuran efisiensi ini mengacu pada Keputusan Menteri Dalam Negeri Nomor 690.900.327 Tahun 1994. Berikut kriteria penilaian efisiensi pada (Tabel 1).

$$
\frac{\mathrm{Wa}}{\mathrm{Wb}} x 100 \%
$$

dimana Wa adalah waktu actual setelah penggunaan alat dan $\mathrm{Wb}$ adalah waktu sebelum penggunaan alat.

Tingkat efektivitas kualitas jamur tiram kurang ideal dapat ditentukan menggunakan Persamaan 3. Pengukuran efektivitas ini mengacu pada Keputusan Menteri Dalam Negeri Nomor 690.900.327 Tahun 1996. Berikut kriteria penilaian efektivitas pada (Tabel 2).

$$
\frac{\mathrm{Kt}}{\mathrm{Ka}} x 100 \%
$$

dimana Kt dan Ka berturut-turut adalah kualitas target dan kualitas aktual jamur tiram kurang ideal.

\section{HASIL DAN PEMBAHASAN}

\subsection{Hasil Perancangan Program Monitoring System}

Pada pemograman rancangan alat menggunakan library, untuk mendefinisikan apa saja yang harus dikerjakan oleh sebuah mikrokontroler. Pada penelitian ini menggunakan URL atau nama alamat website http://febriansaheka.my.id/ dengan menggunakan plugin (software) tambahan File Transfer Protocol (FTP) untuk memindahkan data baris coding dari ATOM menuju web. Tampilan web yang digunakan pada penelitian ini tersusun dari beberapa file dengan ekstensi PHP. PHP dan web server dapat saling terhubung, dikarenakan PHP adalah bahasa yang telah dirancang agar mudah untuk dimasukkan pada halaman HTML, sehingga memudahkan web server dalam membaca file ber ekstensi PHP (Cosentino, 2003).

\subsection{Hasil Perancangan Alat Monitoring System}

Pada hasil perancangan alat ini, saat pertama kali NodeMCU dihubungkan ke power supply dan Wifi dinyalakan maka akan muncul tanda led berwarna biru menyala pada mikrokontroler.

Tabel 1. Keputusan Menteri Dalam Negeri Nomor 690.900.327 Tahun 1994

\begin{tabular}{cc}
\hline Persentase (\%) & Kriteria \\
\hline$>100$ & Tidak Efisien \\
$90-100$ & Kurang Efisien \\
$80-90$ & Cukup Efisien \\
$60-80$ & Efisien \\
$<60$ & Sangat Efisien \\
\hline
\end{tabular}

Tabel 2. Keputusan Menteri Dalam Negeri Nomor 690.900.327 Tahun 1996

\begin{tabular}{cc}
\hline Persentase (\%) & Kriteria \\
\hline$>100$ & Sangat Efektif \\
$90-100$ & Efektif \\
$80-90$ & Cukup Efektif \\
$60-80$ & Kurang Efektif \\
$<60$ & Tidak Efektif \\
\hline
\end{tabular}


Tanda bahwa antara Blynk dan mikrokontroler telah terhubung akan muncul notifikasi "online" di layar tampilan Blynk dan pada serial monitor, selanjutnya pada halaman web akan menampilkan data dari sensor tiap satuan waktu, serta lampu peringatan akan menyala apabila kondisi ruangan kurang ideal dari nilai ambang batas yang telah diatur. Algoritma monitoring serta kontrol telah dikembangkan melalui coding lalu diunggah ke NodeMCU, dengan menggunakan Arduino IDE sebagai elemen inti sistem (Jaber et al., 2019). Hasil perancangan alat dapat dilihat pada (Gambar 3).

\subsection{Hasil Pengujian Sistem dan Analisis Data}

\subsubsection{Hasil Pengujian Perbandingan Antara} Sensor dengan Alat Ukur Standar

Perbandingan dilakukan sebanyak 30 kali dengan interval jeda selama 30 menit, hal ini dipergunakan untuk menunjukkan letak perbedaan akurasi sensor pada sistem kendali dengan alat ukur standar yang ada secara berkala bertujuan untuk kalibrasi sensor, sehingga dapat meningkatkan keandalan sistem kendali saat diterapkan dalam pengambilan data penelitian. Penyesuaian pada penulisan coding diperlukan agar perintah yang dieksekusi oleh mikrokontroler dapat berfungsi dengan baik. Tingkat error antara prototype dengan alat konvensional, harus tidak terpaut jauh nilai yang ditampilkan (Suci, 2018). Adapun 2 parameter yang digunakan sebagai berikut:

\section{a.Parameter Suhu}

Berdasarkan hasil pengujian perbandingan parameter nilai bacaan suhu pada sensor DHT22 dengan alat ukur standar, diperoleh nilai error suhu minimum yang terjadi sebesar $0{ }^{\circ} \mathrm{C}$ dan nilai error suhu maksimum sebesar $1,1^{\circ} \mathrm{C}$. Sensor ini telah berfungsi dengan baik dan dapat di implementasikan untuk mengambil data, hal ini dikarenakan rata-rata error suhu didapatkan nilai $0,33^{\circ} \mathrm{C}$. Menurut Riskiono et al. (2020), ratarata nilai error pembacaan suhu DHT22 adalah $0,465{ }^{\circ} \mathrm{C}$. Datasheet sensor DHT22 memiliki rentang pembacaan nilai suhu $-40^{\circ} \mathrm{C}$ sampai 80 ${ }^{0} \mathrm{C}$ dengan akurasi $\pm 0,5^{\circ} \mathrm{C}$. Hal ini menunjukkan bahwa sensor DHT22 berfungsi dengan baik serta tingkat akurasi, stabilitas, dan sensitivitas pengukuran sensor cukup akurat, karena ketika dibandingkan dengan alat ukur standar hasil dari pengujian masih dalam rentang toleransi error sensor suhu DHT22. Data hasil pengujian dapat dilihat pada grafik (Gambar 4).

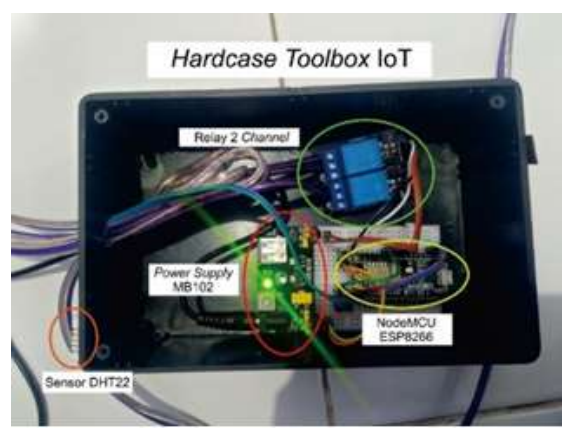

Gambar 3. Hasil Perancangan Alat pada Wadah Penyimpanan Alat

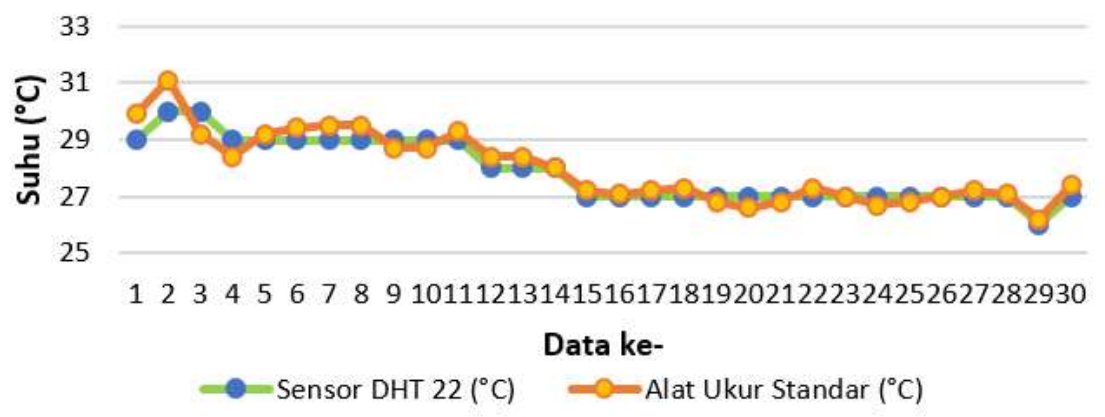

Gambar 4. Grafik Perbandingan Pengujian Alat Suhu Ruang Budidaya Jamur Tiram 
b. Parameter Kelembaban

Berdasarkan hasil pengujian perbandingan parameter kelembaban dari hasil bacaan sensor DHT22 dengan alat ukur standar ruang budidaya jamur tiram, diketahui nilai error minimum dalam pengujian yaitu $0 \%$ RH dan nilai maksimum error yang didapatkan yaitu $5 \% \mathrm{RH}$, kemudian untuk nilai rata-rata error menunjukkan dalam pengujian memperoleh nilai 1,8\% RH. Berdasarkan data yang didapat, pada parameter kelembaban telah memiliki tingkat akurasi, stabilitas, dan sensitivitas yang baik, karena perbedaan nilai error tidak terlalu signifikan, sehingga masih dalam batas toleransi. Dilihat dari datasheet sensor DHT22 tingkat akurasinya berada pada rentang nilai $\pm 2 \% \mathrm{RH}$. Data dari hasil pengujian ditampilkan dalam bentuk grafik dan dapat dilihat pada grafik (Gambar 5).

\subsubsection{Hasil Validasi Pengujian Functionality}

Kalibrasi sensor sistem kendali perlu dipastikan kelayakannya untuk digunakan pada pengambilan data penelitian, dengan cara melakukan validasi menggunakan datasheet sensor DHT22, serta membandingkan rancangan sistem kendali secara utuh untuk digunakan dalam mengambil data pada lokasi penelitian sebelum dan sesudah penerapan rancangan sistem kendali dilakukan. Berdasarkan hasil pengujian fungsi rancangan alat monitoring dapat disimpulkan bahwa $\mathrm{X}=1$, sehingga hasil pengujian kinerja alat telah memenuhi aspek functionality dalam penelitian ini. Dengan demikian alat yang dirancang telah layak untuk diterapkan untuk monitoring ruang budidaya jamur tiram di Rumah Jamur Barokah Jember. Data dari hasil pengujian functionality ditampilkan dalam bentuk tabel berikut ini (Tabel 3) dan hasil pengujian validasi uji kinerja rancangan alat monitoring, ditampilkan dalam bentuk tabel pada web serta dapat dilihat pada (Gambar 6).

\subsection{Implementasi Monitoring Suhu dan Kelembaban pada Ruang Budidaya Jamur Tiram}

Implementasi dilaksanakan pada ruang budidaya jamur tiram di Rumah Jamur Barokah Jember.

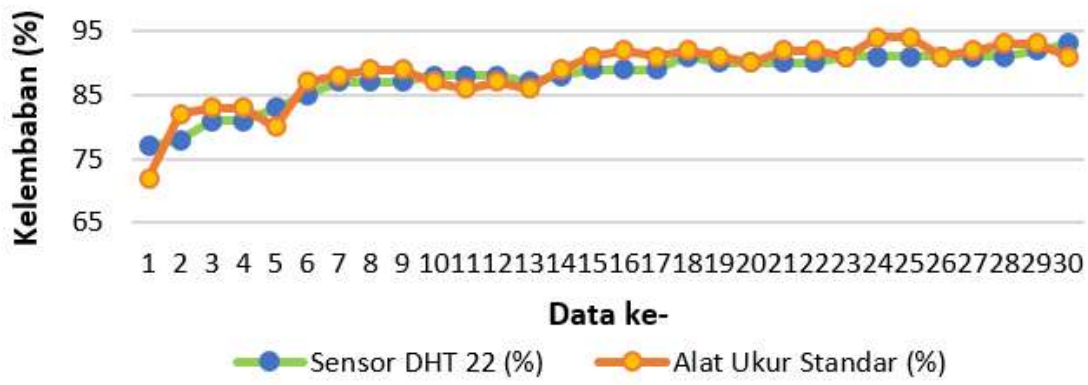

Gambar 5. Grafik Perbandingan Pengujian Alat Kelembaban Ruang Budidaya Jamur Tiram

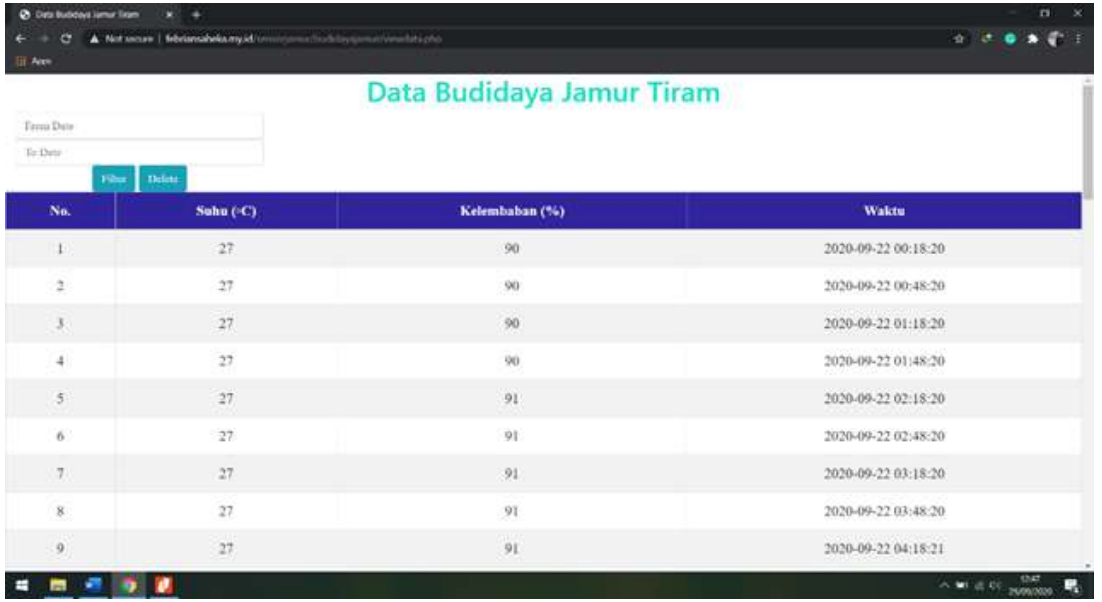

Gambar 6. Data Hasil Uji Kinerja Sistem Kendali pada Ruang Budidaya Jamur Tiram 
Tabel 3. Hasil Pengujian Functionality

\begin{tabular}{clcc}
\hline No & \multicolumn{1}{c}{ Pernyataan } & Ya & Tidak \\
\hline 1. & $\begin{array}{l}\text { Fungsi NodeMCU ESP8266 dalam merekam data sensor dapat ditampilkan pada } \\
\text { serial monitor Arduino IDE }\end{array}$ & 1 & 0 \\
2. & $\begin{array}{l}\text { Fungsi sensor DHT22 dapat membaca data suhu dan kelembaban dengan baik } \\
\text { 3. }\end{array}$ & 1 & 0 \\
& $\begin{array}{l}\text { Fungsi MB102 mengalirkan listrik melalui breadboard menuju NodeMCU dan } \\
\text { Relay }\end{array}$ & 1 & 0 \\
4. & $\begin{array}{l}\text { Fungsi aplikasi Blynk dapat menampilkan beberapa data dari sensor yang } \\
\text { digunakan secara real time dan nirkabel. }\end{array}$ & 1 & 0 \\
5. & $\begin{array}{l}\text { Fungsi Relay 2 Channel dapat memutus dan menghubungkan aliran listrik lampu } \\
\text { peringatan }\end{array}$ & 1 & 0 \\
6. & $\begin{array}{l}\text { Fungsi jaringan hotspot mifi untuk melakukan koneksi dapat digunakan } \\
\text { 7. }\end{array}$ & 1 & 0 \\
& $\begin{array}{l}\text { Fungsi untuk menampilkan data sensor ke web server yang digunakan secara } \\
\text { online dan real time }\end{array}$ & 1 & 0 \\
\hline
\end{tabular}

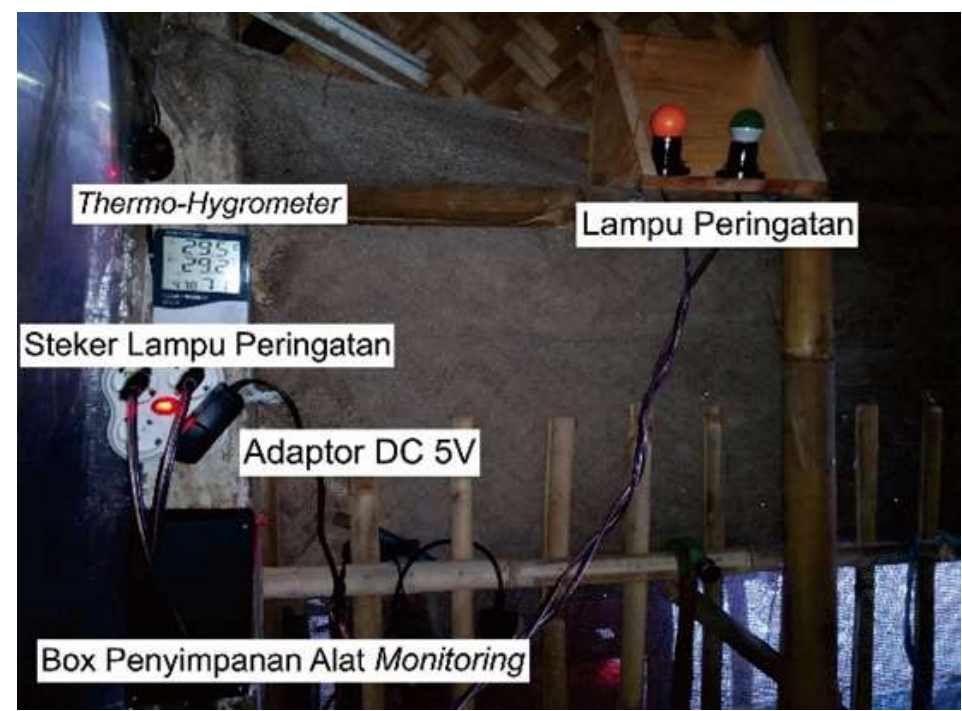

Gambar 7. Posisi Peletakan Wadah Penyimpanan Alat Rancangan Alat Beserta Lampu Peringatan pada Ruang Budidaya Jamur Tiram

Implementasi alat dilaksanakan pada Rabu 23 September 2020 pukul 05.39 WIB sampai dengan Kamis 24 September 2020 pukul 05.39 WIB. Pada penelitian ini, alat monitoring yang telah dirancang ditempatkan pada bagian tengah ruang budidaya berdekatan dengan thermohygrometer digital, hal ini dilakukan agar nilai error tidak terpaut besar dengan alat ukur standar. Peletakan alat pada ruang budidaya jamur tiram dapat dilihat pada (Gambar 7).

Berikut merupakan gambar interface aplikasi Blynk ketika suhu dan kelembaban ruang budidaya jamur tiram lebih dari ideal, ideal, serta kurang dari ideal, dengan pengesetan rentang suhu $25{ }^{\circ} \mathrm{C}-30{ }^{\circ} \mathrm{C}$ dan kelembaban $70 \%-95 \%$ dapat dilihat pada (Gambar 8, 9, dan 10).

\subsection{Analisis Data Hasil Monitoring Suhu dan Kelembaban Ruang Budidaya Jamur Tiram dengan Pengaruhnya Terhadap Efisiensi serta Efektivitas Kinerja} 3.4.1. Kinerja Perancangan Alat Monitoring Hasil pengambilan data dari alat monitoring yang dirancang dapat menunjukkan konsistensi secara real time, penggunaan mifi dalam menyuplai jaringan internet terbilang mumpuni dan didukung dengan lokasi penelitian di daerah perkotaan, sehingga stabilitas transmisi data dari sistem kendali menuju web maupun perangkat kendali dapat berjalan dengan baik. Penggunaan delay 2 menit selama 24 jam pada pengambilan parameter data dapat berjalan konsisten. Hasil monitoring pada ruang budidaya jamur tiram dapat dilihat pada (Gambar 11). 


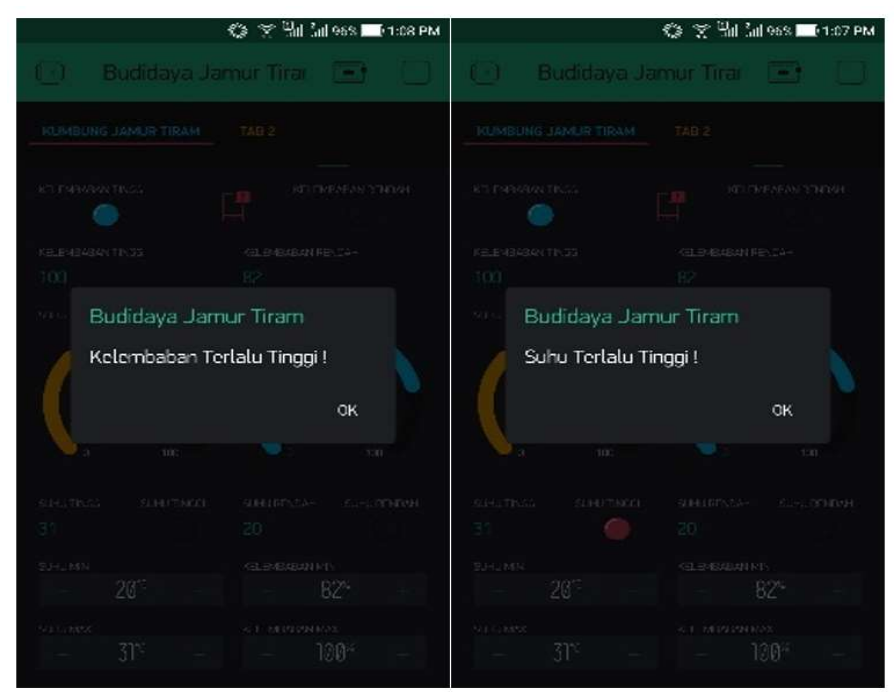

Gambar 8. Interface Aplikasi Blynk Saat Suhu atau Kelembaban Ruang Budidaya Jamur Tiram Lebih dari Ideal

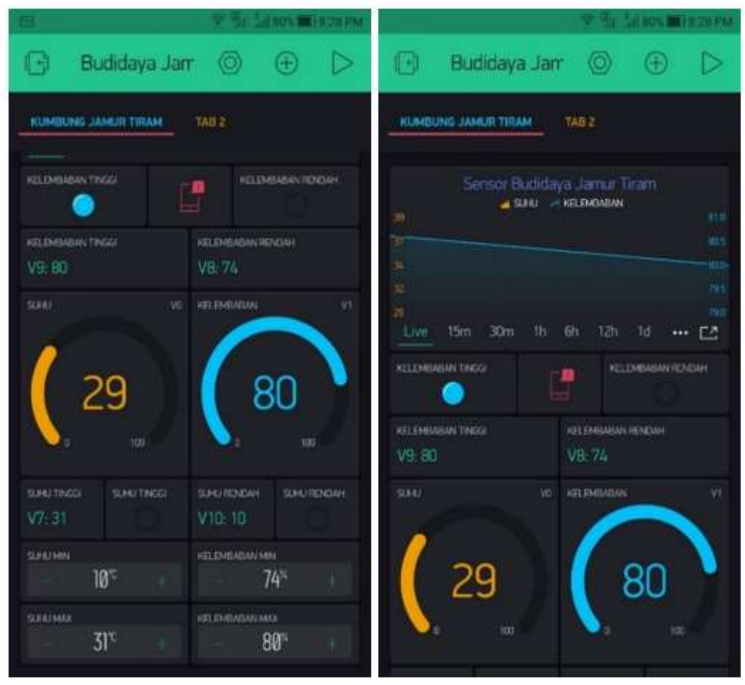

Gambar 9. Interface Aplikasi Blynk Saat Suhu atau Kelembaban Ruang Budidaya Ideal

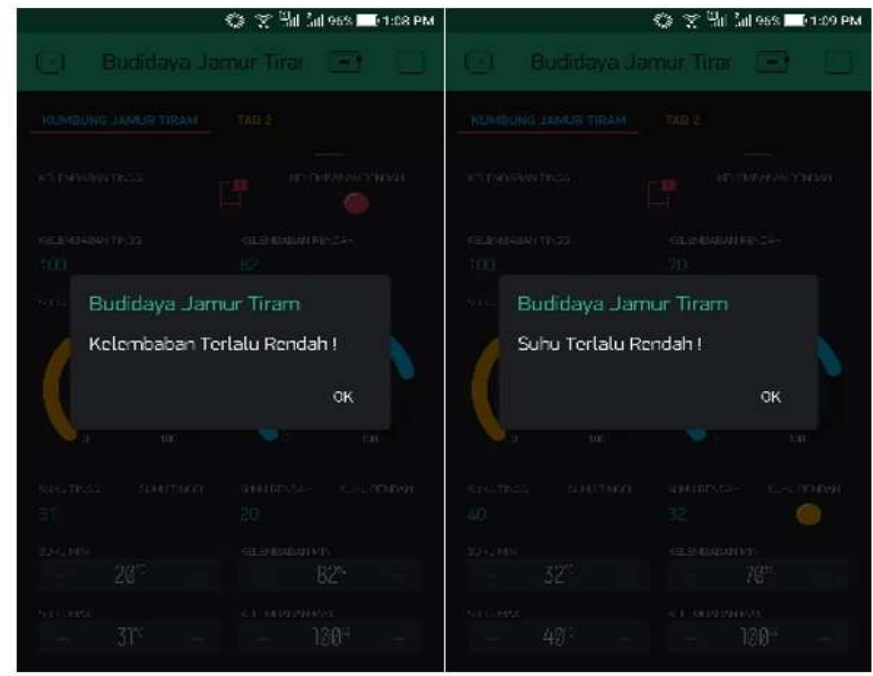

Gambar 10. Interface Aplikasi Blynk Saat Suhu atau Kelembaban Ruang Budidaya Jamur Tiram Kurang dari Ideal 


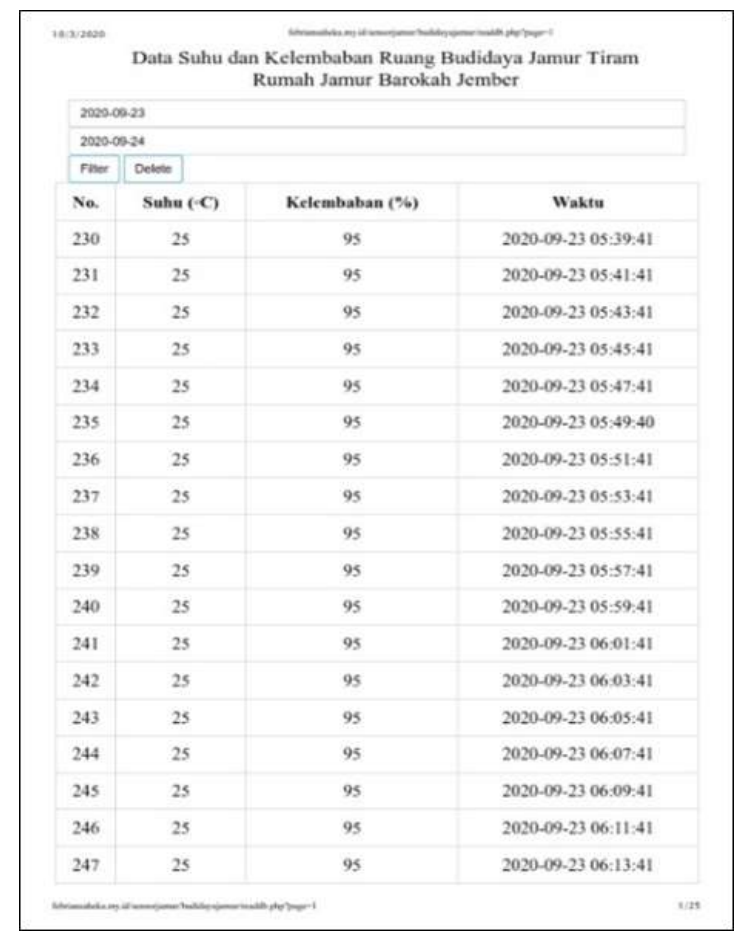

Gambar 11. Data Hasil Monitoring pada Ruang Budidaya Jamur Tiram

Tabel 4. Data Waktu Monitoring Pada Ruang Budidaya Jamur Tiram Sebelum dan Sesudah Implementasi Alat

\begin{tabular}{cccc}
\hline \multirow{2}{*}{ No } & \multirow{2}{*}{ Waktu Pengambilan Data } & \multicolumn{2}{c}{ Waktu Monitoring (detik) } \\
\cline { 3 - 4 } & & Sebelum & Sesudah \\
\hline 1 & 09.00 WIB & 354 & 267 \\
2 & 12.00 WIB & 367 & 315 \\
3 & 15.00 WIB & 327 & 235 \\
\hline & Rata-rata & $\mathbf{3 4 9 , 3 3}$ & $\mathbf{2 7 2 , 3 3}$ \\
\hline
\end{tabular}

\subsubsection{Efisiensi Waktu Monitoring Suhu dan Kelembaban pada Ruang Budidaya Jamur Tiram}

Kegiatan penyemprotan yang dilakukan oleh pemilik usaha Rumah Jamur Barokah dilakukan setiap 3 jam sekali, hal ini dimulai dari pukul 06.00 WIB - 18.00 WIB. Untuk monitoring ruang budidaya jamur tiram dilakukan dengan melakukan pengecekan terhadap nilai pada thermo-hygrometer digital, apakah telah ideal dengan apa yang diinginkan pemilik usaha atau belum yaitu suhu diantara rentang $25{ }^{\circ} \mathrm{C}-30{ }^{\circ} \mathrm{C}$ serta kelembaban sebesar $70 \%-95 \%$, jika kurang ideal maka dilakukan perlakuan penyemprotan agar nilai suhu dan kelembaban menjadi ideal. Berikut pada (Tabel 4) merupakan data penggunaan waktu monitoring jamur tiram pada ruang budidaya jamur tiram oleh pemilik usaha pada 23 September 2020.
Berdasarkan data Tabel 4 dapat dianalisis dan melalui Persamaan 2 dapat dihitung tingkat efisiensi waktu yang mencapai $77,95 \%$. Dilihat dari hasil perhitungan efisiensi waktu dalam penggunaan alat monitoring jamur tiram telah diketahui apabila nilai efisiensi yang didapatkan sebesar $77,95 \%$, besaran nilai tersebut telah masuk pada kriteria efisien mengacu pada Keputusan Menteri Dalam Negeri Nomor 690.900.327 Tahun 1994.

\subsubsection{Efektivitas Kinerja Monitoring Suhu dan Kelembaban pada Ruang Budidaya Jamur Tiram}

Implementasi alat dilakukan selama 24 jam pada ruang budidaya jamur tiram, dimulai dengan peletakan baglog dari ruang inkubasi ke rak kumbung hingga menghasilkan jamur yang siap dipanen. Berikut pada (Gambar 12) merupakan 
tampak nyata dari kualitas jamur yang kurang ideal.

Kualitas jamur yang kurang ideal seperti payung jamur yang tipis hingga tangkai Panjang diakibatkan oleh kondisi lingkungan yang kurang ideal (Pangestu et al., 2018). Sebelum implementasi alat dilaksanakan, akan dilakukan pengambilan data berupa target akumulasi kualitas jamur tiram pada bulan Agustus dan diperoleh rata rata persentase nilai jamur tiram kurang ideal sebesar 14,86\%.
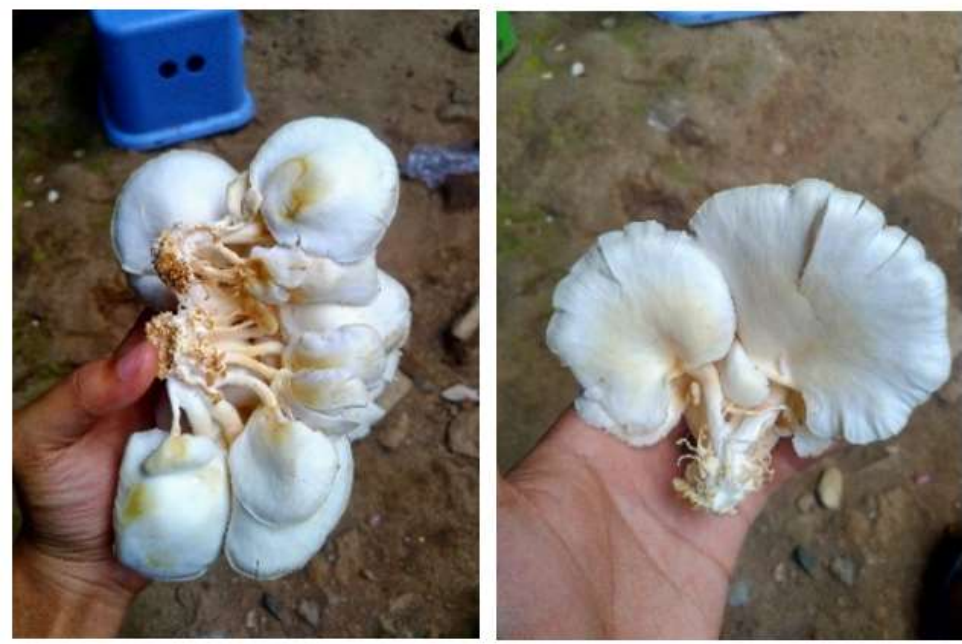

Gambar 12. Kualitas Jamur yang Dipanen Kurang Ideal pada Hari Ke 3

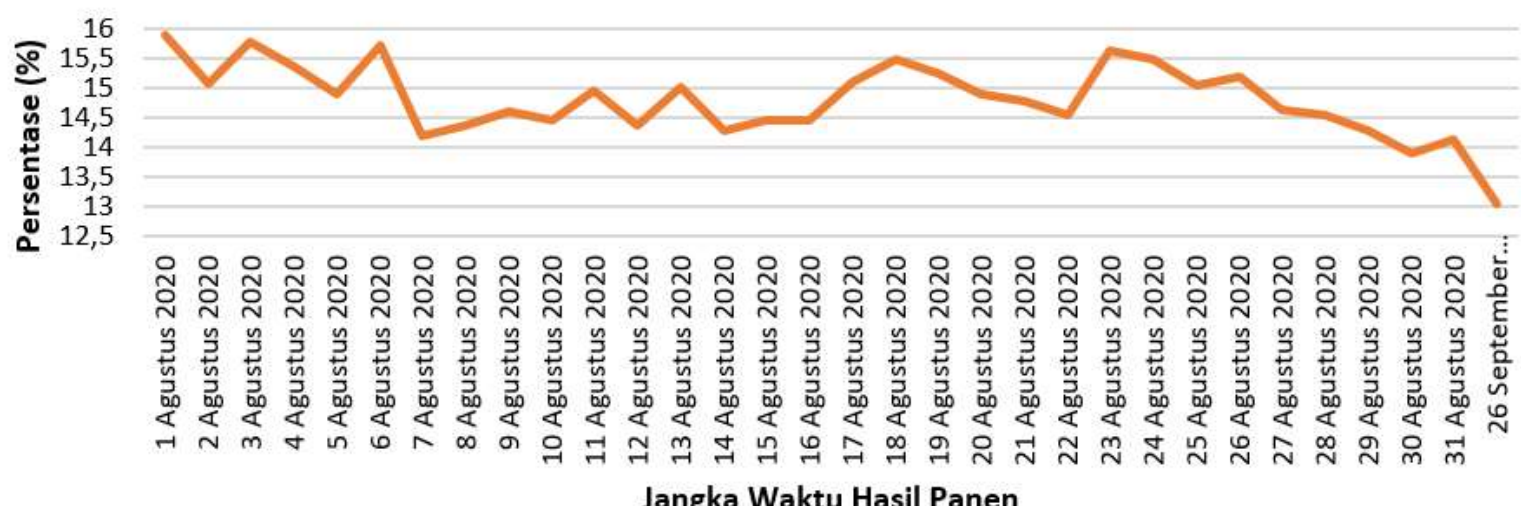

Gambar 13. Grafik Persentase Kualitas Jamur Tiram Kurang Ideal

Tabel 5. Data Hasil Panen Setelah Implementasi Alat

\begin{tabular}{ccccc}
\hline Tanggal & $\begin{array}{c}\text { Jamur Ideal } \\
\mathbf{( k g )}\end{array}$ & $\begin{array}{c}\text { Jamur Kurang } \\
\text { Ideal } \mathbf{( k g )}\end{array}$ & Total (kg) & $\begin{array}{c}\text { Persentase Jamur } \\
\text { Kurang Ideal (\%) }\end{array}$ \\
\hline 26 Sept 2020 & 12 & 1,8 & 13,8 & 13,04 \\
\hline
\end{tabular}


yang didapat dari (jumlah kualitas jamur tiram kurang ideal / total jamur tiram) x 100\% dan lebih kecil jika dibandingkan dengan persentase ratarata 1 bulan terakhir yaitu sebesar $14,86 \%$ dengan target kualitas bulan Agustus dan September adalah sama yaitu maksimal sebesar $21,27 \%$. Untuk memudahkan dalam analisis, maka data hasil pengujian ditampilkan dalam bentuk grafik pada (Gambar 13).

Berdasarkan grafik persentase kualitas jamur tiram kurang ideal mengalami penurunan cukup besar, dibandingkan rata-rata pada bulan agustus yaitu sebesar $1,82 \%$, hal tersebut dikarenakan implementasi alat menjadi faktor pendorong pemilik usaha mudah dalam melakukan pengkondisian ruangan. Berdasarkan perhitungan tingkat efektivitas alat terhadap kualitas jamur yang kurang ideal dapat diketahui bahwa nilai persentase efektivitas sebelum implementasi alat adalah sebesar $143 \%$. Kemudian nilai persentase efektivitas kualitas jamur tiram kurang ideal sesudah implementasi alat adalah sebesar $163 \%$ dan masuk ke dalam kriteria sangat efektif mengacu pada Keputusan Menteri Dalam Negeri Nomor 690.900.327 Tahun 1996. Pembandingan nilai efektivitas alat terhadap kualitas jamur tiram kurang ideal sebelum dan sesudah implementasi alat ini menunjukkan, bahwa nilai efektivitas sesudah implementasi alat lebih besar dibandingkan dengan sebelum implementasi alat.

\section{KESIMPULAN}

Pengaturan suhu dan kelembaban yang diinginkan oleh pengguna dapat dengan mudah langsung diatur melalui perangkat smartphone. Penggunaan lampu peringatan dapat membantu pengguna saat melakukan proses penyemprotan untuk menjadikan suhu serta kelembaban yang ideal tanpa membuka perangkat smartphone, Rancangan alat dinyatakan layak karena hasil validasi functionality menunjukkan nilai 1 , maka alat monitoring dapat berfungsi dengan baik dan dapat di implementasikan. Data hasil yang diperoleh dari alat monitoring pada ruang budidaya jamur tiram, memperlihatkan terjadi peningkatan pada nilai efisiensi waktu sebesar $77,95 \%$. Pada nilai efektivitas kualitas hasil panen jamur tiram menunjukkan persentase sebesar
$143 \%$ menjadi $163 \%$ setelah alat monitoring yang dirancang di implementasikan.

\section{DAFTAR PUSTAKA}

Agustianto, K., Wardana, R., Destarianto, P., Mulyadi, E., dan Wiryawan, I. G. 2021. Development of automatic temperature and humidity control system in kumbung (oyster mushroom) using fuzzy logic controller. In IOP Conference Series: Earth and Environmental Science (Vol. 672, No. 1, p. 012090). IOP Publishing.

Bunluewong, K. 2021. Semi-Automated Mushroom Cultivation House using Internet of Things. Engineering Access, 7(2): 181-188.

Cosentino, C. 2003. Advanced PHP for Web professionals. Prentice Hall Professional.

Devi, N, S., Erwanto, D., Utomo, Y, B., 2018. Perancangan Sistem Kontrol Suhu dan Kelembaban Ruangan pada Budidaya Jamur Tiram Berbasis Internet of Things. Multitek Indonesia: Jurnal Ilmiah, 12(2): $104-113$.

Hamdi, A. S dan E. Baharuddin. 2014. Metode Penelitian Kualitatif. Yogyakarta: Deepublish.

ISO/IEC Standard No. 9126. 2001-2004: Software engineering - Product quality; Parts 1-4. International Organization for Standardization (ISO)/ International Electrotechnical Commission (IEC), Geneva, Switzerland.

Jaber, A. A., Al-Mousawi, F. K. I., dan Jasem, H. S. 2019. Internet of things based industrial environment monitoring and control: a design approach. International Journal of Electrical \& Computer Engineering (20888708), 9(6): 4657-4667.

Keputusan Menteri Dalam Negeri Nomor 690.900.327 tahun 1994 tentang pedoman penilaian dan kinerja keuangan. 
Keputusan Menteri Dalam Negeri Nomor 690.900.327 tahun 1996 tentang pedoman penilaian kinerja keuangan.

Mohammed, M. F., Azmi, A., Zakaria, Z., Tajuddin, M. F. N., Isa, Z. M., \& Azmi, S. A. 2018. IoT based monitoring and environment control system for indoor cultivation of oyster mushroom. In Journal of Physics: Conference Series (Vol. 1019, No. 1, p. 012053). IOP Publishing.

Nurhakim, Y, I. 2018. Sukses Budidaya Jamur Tiram. Jakarta: PT. Serambi Semesta Distribusi.

Pangestu, N, Rizal, M, Rakhmadhany, P. 2018. Implementasi Sistem Monitoring Pada Rumah Jamur Menggunakan Jaringan Nirkabel Berbasis Protokol Komunikasi Message Queuing Telemetry Transport (MQTT). Jurnal Pengembangan Teknologi
Informasi dan Ilmu Komputer, 2 (12): $7496-7501$.

Riskiono, S. D., Prasetyawan, P., Mulyanto, A., Iqbal, M., dan Prabowo, R. 2020. Control and Realtime Monitoring System for Mushroom Cultivation Fields based on WSN and IoT. In Journal of Physics: Conference Series (Vol. 1655, No. 1, p. 012003). IOP Publishing.

Subedi, A., Luitel, A., Baskota, M., dan Acharya, T. D. 2019. IoT Based Monitoring System for White Button Mushroom Farming. In Multidisciplinary Digital Publishing Institute Proceedings, 42 (1): 46.

Suci, D. F. A., 2018. Rancangan bangun Alat Monitorimg Denyut Nadi dan Suhu Tubuh dengan Visualisasi LCD Berbasis Arduino UNO. [Skripsi]. Jember: D3 Teknik Elektro Fak. Teknik UNEJ. 